\title{
Simulation of the Behavior of a Ship Hull under Grounding: Effect of Applied Element Size on Structural Crashworthiness
}

\author{
Aditya Rio Prabowo ${ }^{1} * \mathbb{D}$, Teguh Putranto ${ }^{2}$ and Jung Min Sohn ${ }^{3}$ \\ 1 Department of Mechanical Engineering, Universitas Sebelas Maret, Surakarta 57126, Central Java, Indonesia \\ 2 Department of Civil Engineering and Architecture, Tallinn University of Technology, 19086 Tallinn, Estonia \\ 3 Department of Naval Architecture and Marine Systems Engineering, Pukyong National University, \\ Busan 48513, Korea \\ * Correspondence: aditya@ft.uns.ac.id; Tel./Fax: +62-271-632-163
}

Received: 19 June 2019; Accepted: 12 August 2019; Published: 14 August 2019

\begin{abstract}
This work models the effect of an impact phenomenon-namely the interaction between seabed rock and a ship during its operations-on the ship structure. The collision between a tanker vessel with a conical rock is simulated, a scenario that is similar to the famous grounding of the Exxon Valdez oil tanker. The study uses finite element analysis to simulate numerical parameters that are related to structural response and the contours of the ship hull under impact loading. The traditional element-length-to-thickness (ELT) ratio of 10 is recommended in this work. ELT ratios in the range of 11 to 13 are shown to produce similar results in terms of internal energy, contact force, and structural acceleration. Additionally, the analysis time is reduced by approximately $20 \%$ for the recommended ELT ratio. This result is very helpful for researchers using finite element analysis to simulate ship accidents, since the mesh size or length of complex structures is used to maintain the efficiency and accuracy of the simulation results.
\end{abstract}

Keywords: impact phenomena; ship-rock interaction; finite element analysis; mesh size; structural response; damage patterns

\section{Introduction}

Developments in engineering and science have led to demands for more complex analysis and the observation of research subjects, including marine structures. It is well known that better approximation and prediction leads to adequate safety. In the field of marine structures, safety is primarily related to accidents that occur on any structure or vessel in the daily operations of shipping and offshore industries [1-3]. Massive accidents, including oil spillage, loss of life, and environmental damage, are likely to occur, and in certain cases are unavoidable. Efforts to avoid damage to ship hulls have concentrated on methods for the sustainable improvement of navigating instruments and mitigation plans. Additionally, design plans for various vessels, such as those carrying dangerous cargo, take into account resistance against impacts, the most frequent types of which are grounding and explosion. Such impacts have been studied while using several methods, including the finite element method, which has been used in various studies since the 1990s. This method is capable of simulating almost any type of phenomenon, including impacts in maritime environments. However, despite the advantages of the finite element method, challenges that are associated with the idealization of actual phenomena in numerical design have to be addressed in order to obtain effective results [4] while maintaining calculation accuracy. The mesh size is an important factor in the finite element method, and the selection of an appropriate mesh size when modeling complex objects, such as ship hulls, is therefore also important. This is also important when simulating impact events. For instance, 
loading causes the modeled material to surpass its linear limit, thereby leading to nonlinearity due to structural complexity. Larger mesh sizes allow for a faster calculation time, however with less accurate results. Conversely, when the mesh size is too small, high accuracy is achieved at the cost of a large processing time. Large processing times represent a huge disadvantage due to the limitations of computational capability to carry out nonlinear analysis. In previous research that was related to the effect of accident phenomena on ship hull structures, element-length-to-thickness (ELT) ratios of 5-10 were used to control the finite element mesh size [5-7]. However, it is possible to expand the range of ELT ratios to provide faster calculation times with high accuracy. Therefore, it is necessary to examine and verify the use of an expanded range of ELT ratios in simulations of the effects of accidents on marine structures.

Therefore, this work aimed to investigate the structural response and damage pattern of a ship hull using a finite element model with an expanded ELT ratio and to compare the results with those obtained using a traditional ratio. The accidental scenario involved the grounding of a chemical tanker carrying a dangerous cargo, with oceanic rock that indents the vessel structure. Structural performance was assessed via internal energy, crushing force, and damage pattern, and the effect of the expanded ELT ratio was quantified.

\section{Brief Review of Pioneering Works}

\subsection{Structural Performance Studies}

Studies of accidental phenomena in maritime environments began after the occurrence of major shipping incidents across the globe. Such incidents have caused collateral damage to maritime ecosystems, leading to the loss of human life, the creation of major environmental revitalization funds, difficulties in evacuation, and long-term effects on the socioeconomic conditions of societies close to the incident locations. In recent decades, there has been a high demand to ensure safety as the Northern Sea Route (NSR) has been opened for international shipping from Asia to Europe and America. Accidental damage to ship hulls causes serious damage to the Arctic environment, which is considered to be a critical location for the ozone hole and global warming. Therefore, various studies have been conducted on shipping and operational safety, including structural performance.

Accidental events are serious threats to the integrity of ship hulls and their surroundings, including crew, passengers, and the maritime environment. As summarized in Tables 1 and 2, the structural performance of ship hulls has been significantly improved when compared to the conventional design, especially in terms of single and double hulls. The internal energy and crushing force are primary considerations in the assessment of crashworthiness. Additionally, the behavior of drivers has been predicted for girders during collision and grounding. Furthermore, the surface of the ship hull has also been investigated in studies regarding load explosion.

Table 1. Summary of previous studies of the structural performance of ship hulls after collision.

\begin{tabular}{|c|c|c|c|}
\hline Author & Phenomenon & Subject & Conclusions \\
\hline Ozguc et al. [8] & Collision & Bulk carrier & $\begin{array}{l}\text { The collision energy absorption } \\
\text { capability depends on the thickness } \\
\text { of structural parts, such as the outer } \\
\text { and inner shells and side stringers. }\end{array}$ \\
\hline Haris and Amdahl [9] & Collision & Shuttle tanker & $\begin{array}{l}\text { Collisions in which both ships } \\
\text { deform. The damage and energy } \\
\text { dissipation switches between ships } \\
\text { during the collision. }\end{array}$ \\
\hline Prabowo et al. [10] & Collision & $\begin{array}{l}\text { Passenger ship; Tanker; } \\
\text { Reefer cargo }\end{array}$ & $\begin{array}{l}\text { It was demonstrated that the } \\
\text { structural crashworthiness of the } \\
\text { struck ship during rebounding was } \\
\text { different than for fully stuck cases. }\end{array}$ \\
\hline
\end{tabular}


Table 2. Summary of the previous works in terms of structural performance under grounding and explosion.

\begin{tabular}{|c|c|c|c|}
\hline Author & Phenomenon & Subject & Conclusions \\
\hline Yu et al. [11] & Grounding & Tanker & $\begin{array}{l}\text { Up to an indentation of } 90 \% \text { of the } \\
\text { double-bottom height, other double-bottom } \\
\text { structural components contribute little to the } \\
\text { total energy dissipation during distortion; } \\
\text { therefore, it can be neglected. }\end{array}$ \\
\hline Sormunen et al. [12] & Grounding & Tanker & $\begin{array}{l}\text { The relationship between the volume of } \\
\text { damaged material and the real rock area or } \\
\text { model projected area was found to be linear for } \\
\text { the whole grounding simulation and less than } \\
\text { the vertical phase of the grounding model. }\end{array}$ \\
\hline Prabowo et al. [13] & Grounding & Tanker & $\begin{array}{l}\text { The bottom shell was found to be the } \\
\text { component which experienced the highest } \\
\text { plastic deformation during grounding. }\end{array}$ \\
\hline Qiankun and Gangyi [14] & Explosion & $\begin{array}{l}\text { Idealized as } 1 / 4 \text { of the } \\
\text { ship section }\end{array}$ & $\begin{array}{l}\text { The effects of alpha damping to the velocity } \\
\text { response were investigated, with the alpha } \\
\text { damping significantly reducing at later times } \\
\text { and low frequency response considering the } \\
\text { effects of hydrodynamic drag. }\end{array}$ \\
\hline Ming et al. [15] & Explosion & $\begin{array}{l}\text { Idealized as a } \\
\text { stiffened plate }\end{array}$ & $\begin{array}{l}\text { The detonation wave propagates into the water } \\
\text { and the hull plate; therefore, an instantaneous } \\
\text { high-pressure is produced on the plate, which } \\
\text { is up to } 700-800 \mathrm{MPa} \text { in a zone whose radius is } \\
\text { close to the radius of the charge. The stiffeners } \\
\text { seem to have no response during this process. }\end{array}$ \\
\hline
\end{tabular}

\subsection{Methods for the Simulation of Impact Phenomena}

The choice of methodology for the analysis of impact phenomena is important for obtaining dependable estimates and determining the effect of the input parameters. In the early 1950s, direct investigations of accidental phenomena were initiated to improve methods for the simulation of impact phenomena. Based on these investigations, empirical formulas were developed by several researchers, such as Minorsky [16] and Woisin [17]. Later, large-scale experiments were used to obtain realistic data without depending on actual accidents. Japan, the Netherlands, and Germany were active in performing such experiments. Subsequently, smaller-scale experiments were conducted, such as the plate cutting experiment of Simonsen [18] and the stiffened plate impact experiment of Alsos [19]. As the development of computational instruments has advanced, numerical methods have been used to simulate accidental events since the early 1990s. In particular, the finite element method emerged as one of the most popular methods for simulating various impact scenarios. This method has a huge advantage, in that failure analysis can be directly re-calculated. Tables 3 and 4 detail pioneering works related to the calculation of impact phenomena in maritime environments.

Table 3. Calculation methods used in pioneering works related to ship collision.

\begin{tabular}{|c|c|c|c|}
\hline Author & Phenomenon & Method & Conclusions \\
\hline Prabowo et al. [20] & Collision & Finite element method & $\begin{array}{l}\text { Implementation of a wider } \\
\text { double hull was considered a } \\
\text { good option to increase safety; } \\
\text { however, the ship's capacity } \\
\text { would be reduced. }\end{array}$ \\
\hline Reardon and Sprung [21] & Collision & Empirical approach & $\begin{array}{l}\text { Minorsky's ship collision } \\
\text { model was validated and the } \\
\text { probability of damaging a } \\
\text { radioactive material during } \\
\text { collision was estimated. }\end{array}$ \\
\hline
\end{tabular}


Table 4. Calculation methods used in pioneering works related to grounding and explosion.

\begin{tabular}{|c|c|c|c|}
\hline Author & Phenomenon & Method & Conclusions \\
\hline Zhiqiang et al. [22] & Grounding & $\begin{array}{l}\text { Simplified approach; } \\
\text { Finite element method }\end{array}$ & $\begin{array}{l}\text { Notably, the vertical component of the } \\
\text { grounding force induced heave and pitch } \\
\text { motions of the hull. Initial contact was likely to } \\
\text { take place in the bow area, where the hull } \\
\text { responds most readily to pitch motions. }\end{array}$ \\
\hline Prabowo et al. [23] & Grounding & $\begin{array}{l}\text { Scaled experiment; } \\
\text { Finite element method }\end{array}$ & $\begin{array}{l}\text { It was found that the plate tended to provide } \\
\text { more resistance in perpendicular grounding, } \\
\text { while the internal energy of the stiffener was } \\
\text { dominant during oblique groundings. }\end{array}$ \\
\hline Abubakar and Dow [24] & Grounding & $\begin{array}{l}\text { Scaled experiment; } \\
\text { Finite element method }\end{array}$ & $\begin{array}{l}\text { The effect of grounding was highly localized in } \\
\text { all simulations, with high stress contours only } \\
\text { occurring in the area close to the impact. }\end{array}$ \\
\hline Zong et al. [25] & Explosion & $\begin{array}{l}\text { Scaled experiment; } \\
\text { Finite element method }\end{array}$ & $\begin{array}{l}\text { Damage modes were classified according to the } \\
\text { standoff distance between the charge and the } \\
\text { ship. This is helpful for the analysis of the } \\
\text { surface of the ship when subjected to } \\
\text { underwater explosion. }\end{array}$ \\
\hline
\end{tabular}

The impact phenomena and calculation methods that are mentioned in Tables 3 and 4 are closely related to the highly dynamic nonlinear characteristics needed to properly idealize the finite element approach. The time constraints of the scenario simulations are highly influenced by the numbers of discrete elements that are used to represent the structures of large ships. Structural performance needs to be assessed to determine reasonable mesh sizes in impact analysis.

\section{Analysis Methods}

\subsection{Calculation Algorithm}

An explicit strategy using the ANSYS LS-DYNA finite element method [26] and the central difference time integration method was applied in this study to simulate a highly dynamic nonlinear impact phenomenon, i.e., ship grounding. The accelerations at time $t$ were evaluated while using Equation (1), while the velocity and displacement were obtained using Equations (2) to (4). The stability limit of the explicit strategy must be maintained to obtain a stable solution. The time step must be smaller than the critical value, as presented in Equation (5). In this research, the critical time step refers to the Courant-Friedrichs-Lewy condition.

$$
\begin{gathered}
\left\{a_{t}\right\}=[M]^{-1}\left(\left\{F_{t}^{e x t}\right\}-\left\{F_{t}^{i n t}\right\}\right) \\
\left\{v_{t+\Delta t / 2}\right\}=\left\{v_{t-\Delta t / 2}\right\}+\left\{a_{t}\right\} \Delta t_{t} \\
\left\{u_{t+\Delta t}\right\}=\left\{u_{t}\right\}+\left\{v_{t+\Delta t / 2}\right\} \Delta t_{t+\Delta t / 2} \\
\left\{x_{t+\Delta t}\right\}=\left\{x_{0}\right\}+\left\{u_{t+\Delta t}\right\} \\
\Delta t \leq \Delta t^{\text {crit }}=\frac{2}{\omega_{\max }}
\end{gathered}
$$

where $\omega_{\max }=2 \frac{c}{l}$ (model is assumed as a rod in the concept algorithm [26]), $[M]$ denotes the mass matrix of the model, $\left\{F_{t}^{\text {ext }}\right\}$ is the applied external body force vector, $\left\{F_{t}^{\text {int }}\right\}$ is the internal force vector, $\left\{a_{t}\right\}$ is the acceleration of the system at time $t,\left\{v_{t}\right\}$ is the velocity of the system at time $t,\left\{u_{t}\right\}$ is the displacement due to the velocity of the system at time $t,\left\{x_{0}\right\}$ is the initial condition of the modeled system or geometry, $\left\{x_{t}\right\}$ is the updated displacement/condition of the modeled system in the numerical analysis, $\Delta t$ is the size of the time step, $\Delta t^{\text {crit }}$ is the size of the critical time step, $\omega_{\max }$ is the largest natural circular frequency, $c$ is the wave propagation velocity, and $l$ is the rod length that is considered in the algorithm assumption. 


\subsection{Geometry and Material}

The ship was an idealized double hull oil/chemical tanker with dimensions as given in Table 5 . Figure 1 presents the double bottom part of the ship's three-dimensional (3D) geometry. The numerical model of the bottom structure defined in ANSYS LS-DYNA [26] with reference to the shell elements was used in this study. The element formulation utilized the fully integrated version of the Belytschko-Tsay $[27,28]$ to suppress hourglass energy during the application of accidental loading to the ship structures.

Table 5. Principal parameters of the ship in the numerical model.

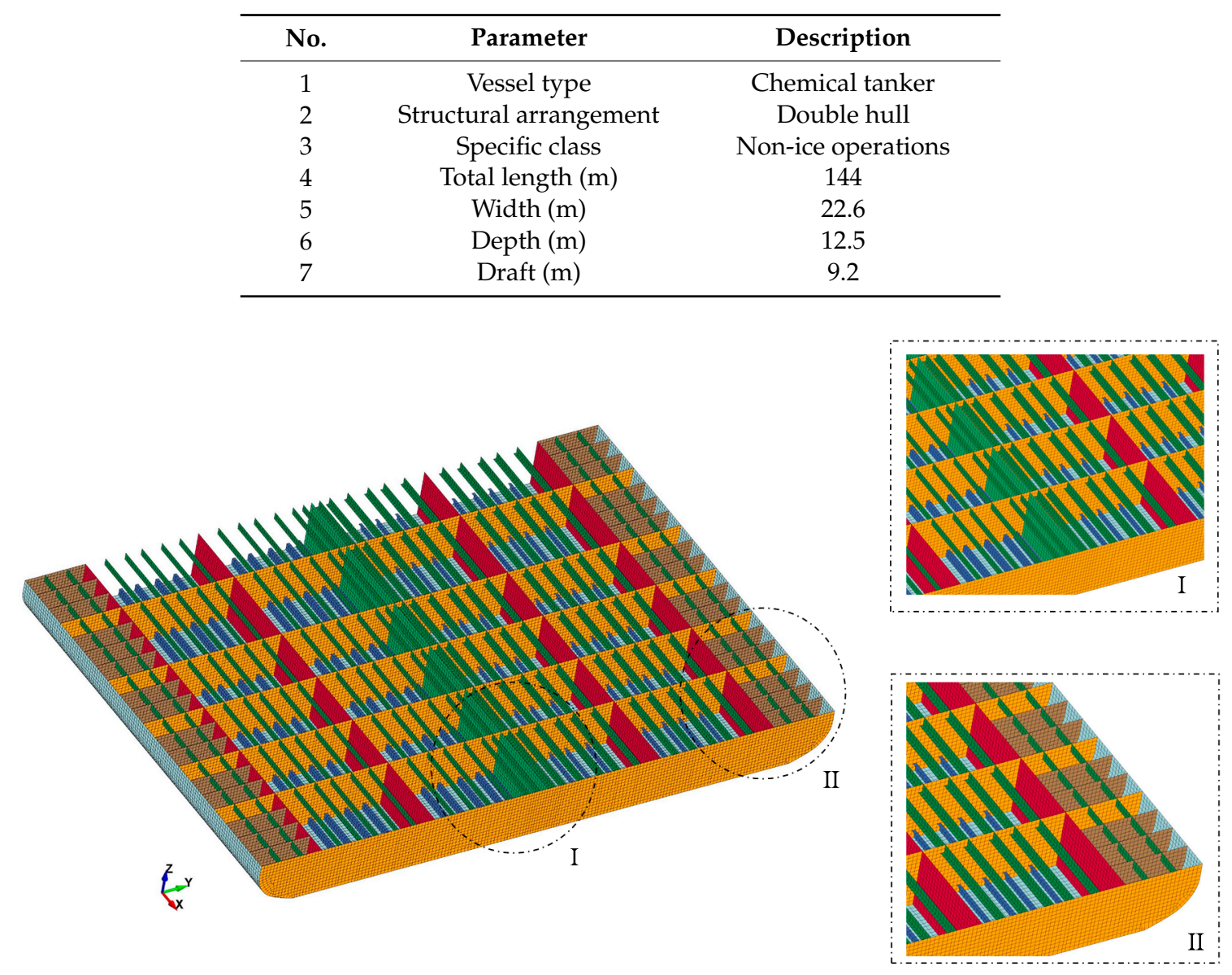

Figure 1. Idealized ship hull used in the numerical calculation with modeling, focusing on the double bottom structures.

In the analysis, steel was defined while using a plastic-kinematic model (see Table 6) with kinematic hardening being applied to the structure. It was assumed that the ship suffered massive damage during the impact. Therefore, it was necessary to define the failure state of the double bottom. The failure limit was assumed to be the strain limit beyond which the material experiences failure under excessive loading.

The proposed strain limit ranges from 0.2-0.35; a value of 0.2 was adopted for the current configuration that is based on a pioneering analysis of an accident scenario involving a bulk carrier by Ozguc et al. [8] and an investigation of ship collision mechanics [29]. Material sensitivity was considered by applying two Cowper-Symonds parameters to the model. 
Table 6. Materials and fixation used for the ship hull in the numerical model.

\begin{tabular}{ccc}
\hline No. & Property/Parameter & Description \\
\hline 1 & Material model & Plastic-kinematic model \\
2 & Element type & Shell \\
3 & Characteristic & Deformable \\
4 & Density $\left(\mathrm{kg} \mathrm{m}^{-3}\right)$ & 7850 \\
5 & Elastic modulus $(\mathrm{MPa})$ & 210,000 \\
6 & Poisson's ratio & 0.3 \\
7 & Yield strength $(\mathrm{MPa})$ & 315 \\
8 & Hardening exponent & 0 \\
9 & Cowper-Symonds Parameter $1\left(\mathrm{C} ; \mathrm{s}^{-1}\right)$ & 3200 \\
10 & Cowper-Symonds Parameter 2 $(p)$ & 5 \\
11 & Failure strain & 0.2 \\
12 & Axial constraint & All displacements \\
13 & Rotational constraint & All rotations \\
\hline
\end{tabular}

\subsection{Rock Parameters}

In this research, the impacting rock was assumed to have a conical geometry, as shown in Figure 2. This rock design was first used by Wierzbicki $[30,31]$ to simulate the damage that was caused to the Exxon Valdez. The rock type was assumed to be pyroxene, one of the primary minerals in oceanic crust. The rock model and its displacement constraints are summarized in Table 7. During interaction with the ship structure, contact was assumed to be surface-to-surface, with consideration of the friction coefficient. The value of the Coulomb friction coefficient ranged from 0.2-0.4; this range is frequently adopted for the modeling of steel-to-steel contact and steel-to-rock contact.

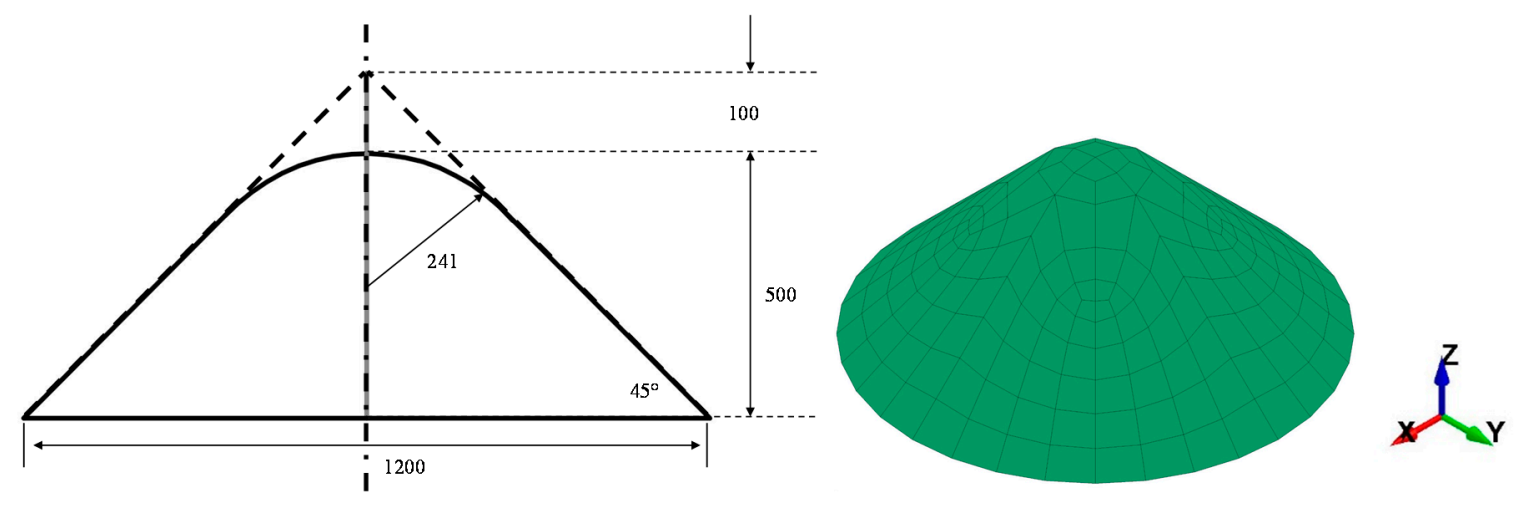

Figure 2. Geometry of the rock indenter used in the impact simulation.

Table 7. Modeling parameters and geometrical constraints for the selected rock design.

\begin{tabular}{ccc}
\hline No. & Property/Parameter & Description \\
\hline 1 & Material model & Rigid \\
2 & Element type & Solid \\
3 & Characteristic & Undeformable \\
4 & Density $\left(\mathrm{kg} \mathrm{m}^{-3}\right)$ & 4002 \\
5 & Elastic modulus (MPa) & 147,000 \\
6 & Poisson's ratio & 0.281 \\
7 & Axial constraint & y-and z-axis displacements \\
8 & Rotational constraint & All rotations \\
\hline
\end{tabular}

\subsection{Design of Accident Scenario}

In this study, interaction in the accidental event was defined as contact between the ship and the rock (rock-structure interaction; RSI). A fundamental case of powered hard grounding was considered 
as the main reference for the scenario configuration. During RSI, the following constraints were imposed: (1) the bottom structure of the ship was fixed on the centerline and (2) both axial and rotational displacements were restrained and applied to the end of the ship's inner bottom, bilge, and shells. The average speed of an oil tanker 50 years ago was $13-18$ knots $\left(6.69-9.26 \mathrm{~ms}^{-1}\right)$, as recorded by the American Society of Naval Engineers [32]. However, in this research, it was assumed that several updates had been made to the machinery of the tanker during its design stage, and therefore a ship velocity of $10 \mathrm{~ms}^{-1}$ was assumed for the RSI. In the automotive industry, the typical element length that was used for crash simulations is approximately 5-10 times larger than the element thickness [33,34]. In the present study, various mesh sizes were used in the finite element method to investigate the effect of the element length on the deformable structure (the ship). The mesh sizes were determined based on the traditional ELT ratio of 10 (Haris and Amdahl [9]), with several ratios that ranged from 11-13 being investigated to determine the optimal ratio.

\section{Structural Crashworthiness of Tanker}

\subsection{Internal Energy}

The structural response of the tanker under accidental loading was evaluated using the energy criterion. The internal energy is representative of the crushing energy that deforms and destroys the deformable structure upon impact. Figure 3 summarizes the results for various mesh sizes. A time $t$ in the initial rock penetration was obtained for the traditional (10) and expanded (11-13) ELT ratios. The differences in penetration between the smallest (10) and largest (13) ELT ratios exceeded $1.5 \mathrm{~m}$, which accounted to a difference of $6.73 \%$. For the next $1 \mathrm{~m}$ of penetration, the results for an ELT ratio of 13 were more similar to those for a ratio of 10 , with the penetration being $5.37 \%$ lower for the ELT ratio of 13. By the end of the penetration period, the difference in internal energy between the investigated ELT ratios had not surpassed $8 \%$, while the smallest difference was $4 \%$. This finding indicates that there is no significant difference between the traditional and recommended ELT ratios. The fully integrated element formulation that was used in this study was verified while using the hourglass energy, which was successfully suppressed and disappeared during calculation.

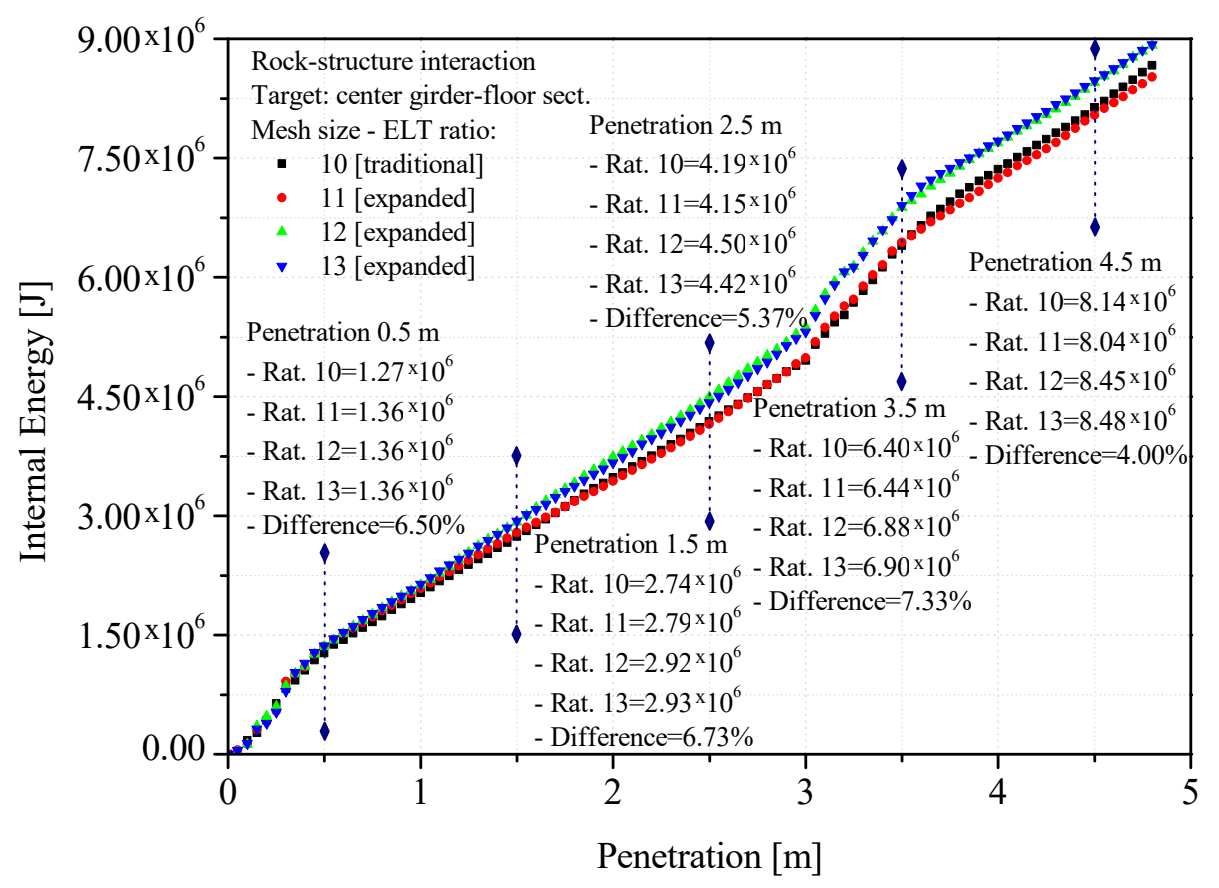

Figure 3. The simulated internal energy as a function of rock penetration for different element-length-to-thickness (ELT) ratios. The traditional ratio is analyzed by following rules in [9]. 


\subsection{Crushing Force}

The failure or rupture behaviors of the deformable structure (the ship) can be observed on the graph of rock penetration against crushing force (Figure 4). In this research, only the ship was modeled as a deformable entity, and the crushing force presented on the graph therefore solely represents the progressive crushing of the ship. It was found that a large force occurred early in the RSI; this represents the first local deformation of the structure. With increased rock penetration into the structure, the transverse floor was breached and the crushing force gradually decreased as a tear opened in the bottom shell. Between two transverse floors, the fluctuation of the crushing force resulted in a stable state with no significant increment. One reason for the large fluctuation of crushing force in the penetration range of $0-1 \mathrm{~m}$ is the velocity that was applied in this study, which is higher than that used in other studies. If a lower velocity were to be applied in the simulation, the fluctuation of crushing force would likely be more uniform and lower in magnitude.

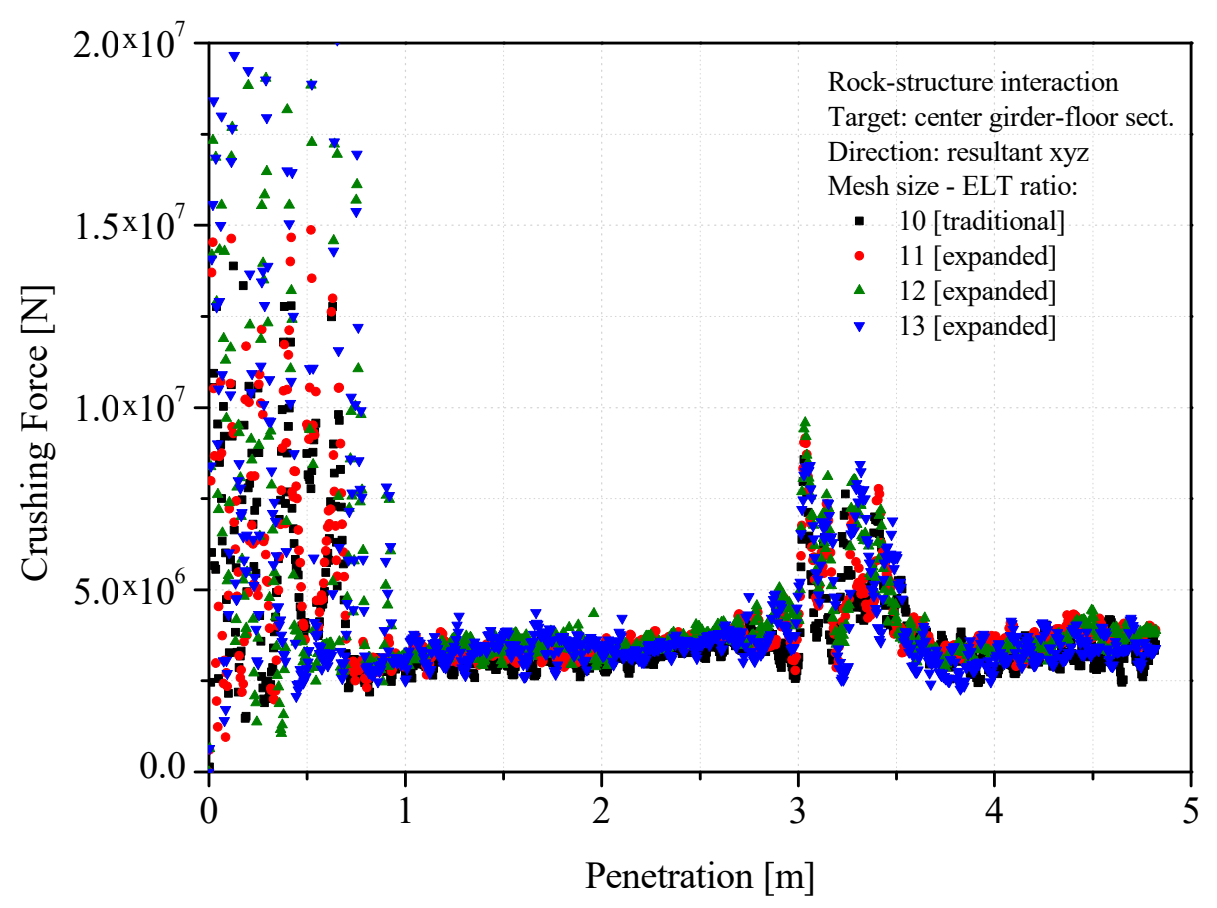

Figure 4. Simulated crushing force as a function of rock penetration.

The next notable fluctuation in crushing force occurred when the second transverse floor started to deform and was finally breached. The connections consisted of longitudinal (center girder) and transverse (floor), and they provided better resistance against accidental loading compared to other parts of the modeled structure. This was also noted by Prusty and Satsanagi [35] in their analysis of stiffened shell structures. The crushing force that was simulated for ELT ratios of 12-13 exhibited greater fluctuation, and reached a peak in the penetration range of $0-1 \mathrm{~m}$. Penetration of 3-3.5 m produced a high fluctuation of crushing force, which was related to the connection between the transverse floor and the longitudinal girder, thereby increasing the structural resistance. This phenomenon was observed for all of the applied mesh sizes, which confirms the strong structural behavior of the bottom part of the hull. Additionally, a very high fluctuation of crushing force occurred during the initial contact between the structure and rock, with this force finally decreasing after penetration reached $1 \mathrm{~m}$. At this penetration, the part of the ship that was first impacted by the rock, i.e., the transverse floor, was completely breached, and the bottom plate was cut.

Subsequently, more specific investigation was conducted by observing the variation of crushing force in the longitudinal direction. Figure 5 shows the results. The crushing force was similar for all selected ELT ratios. Similar degrees of damage were simulated for all mesh sizes. Furthermore, 
large fluctuations in crushing force were recorded when the second transverse floor was breached at penetrations of 3-4 m. The crushing force tended to increase in the minus area as the rock penetrated in the negative longitudinal direction.

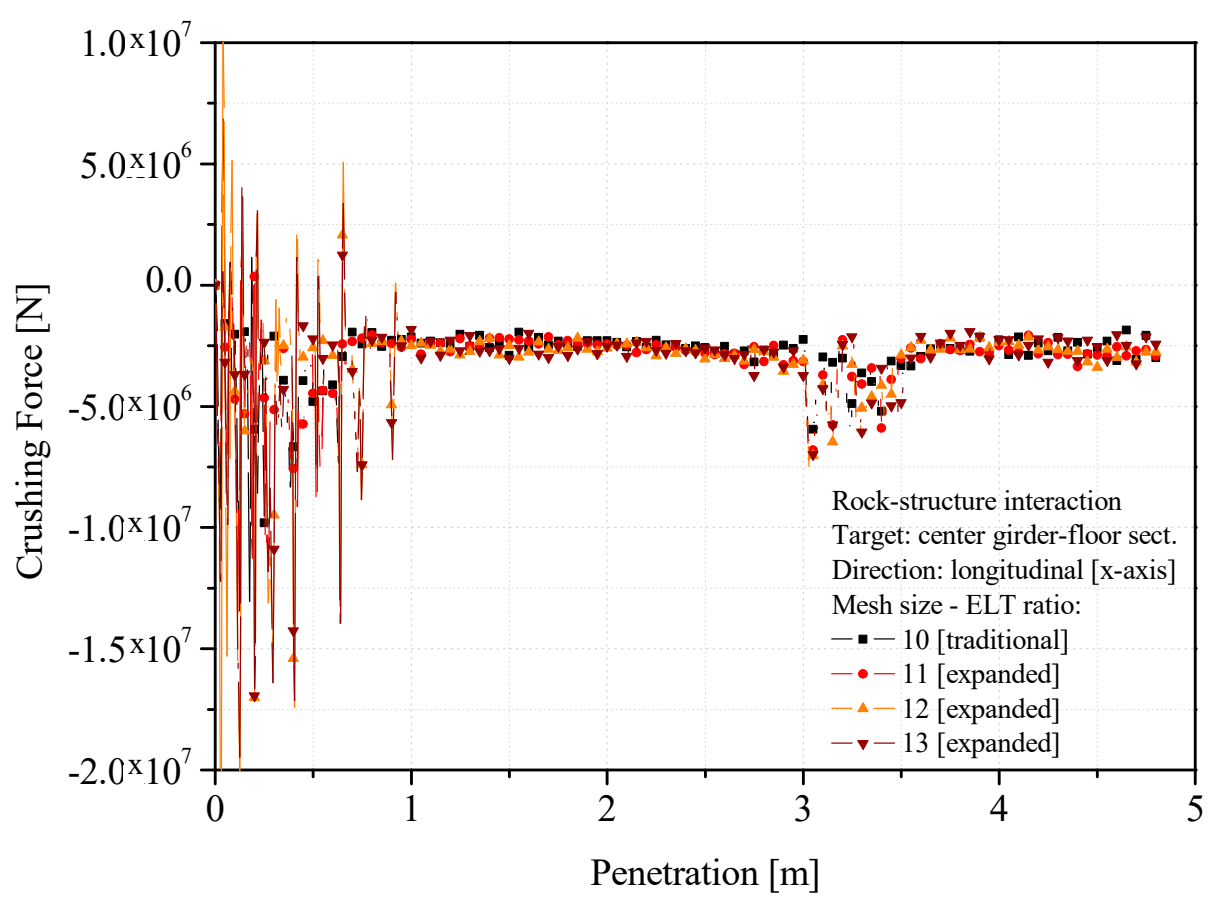

Figure 5. Variation of crushing force in the longitudinal direction (x-axis).

Next, the variation of crushing force in the transverse direction was investigated. Figure 6 shows the results. The simulated forces were similar to those that are shown in Figure 5, especially after the initial RSI occurred. No significant fluctuation in crushing force was observed during the breaching of the second floor, as the damage in the transverse direction was very low. This finding is also supported by the tendency of the force, which was almost 0 states during the RSI. The crushing forces fluctuated less in the transverse direction (y-axis), even during the breach of the second transverse floor, when compared to the variation of crushing force in the longitudinal direction (x-axis). Similar fluctuations were observed for all mesh sizes after the tearing damage had progressed to the bottom shell. The variation of crushing force in the vertical direction (Figure 7) was similar to that in Figure 6. The variation in crushing force that was obtained with the traditional ELT ratio of 10 was shown to match with that obtained with an ELT ratio of 11 at penetrations of $0-1 \mathrm{~m}$.

At penetrations of 0-1 m, a similar tendency of crushing force was observed for an ELT ratio of 12 as compared to that observed for an ELT ratio of 13. Fluctuations in crushing force were observed when the second floor was breached. Based on the evaluation of the simulated crushing force for all observed axes, it can be seen that the RSI caused major damage in the vertical direction (z-axis). The evaluation of the crushing force tendency verified the results for the internal energy. These findings suggest that the crushing force should be calculated in individual directions.

\subsection{Damage Pattern}

Damage to the ship was evaluated by investigating the von Mises (v-M) stress and failure strain, as shown in Figures 8 and 9, respectively. The v-M stress was mainly observed on the girder and plate for an ELT ratio of 10, with the stress expanding to the transverse floors for an ELT ratio of 11. For ELT ratios of 12 and 13, higher v-M stress was observed on the floors, while v-M stress expanded to other girders for an ELT ratio of 13. The length of tearing in the girder and plate was found to be the same as the uniform velocity that was applied in the scenario. However, the v-M stress level showed a 
gradual reduction for different ELT ratios. This indicates that the ship structure experiences failure more easily due to accidental events for larger ELT ratios. The use of large ELT ratios directly affects the mesh size, which also increases the sensitivity of the ship to structural damage. This finding is supported by the results for the failure strain. The structural failure was found to greater for larger ELT ratios. The advantage of using large mesh sizes for finite element calculations is that less processing time is required. However, time constraints are a major factor in numerical experiments for complex structures and nonlinear phenomena.

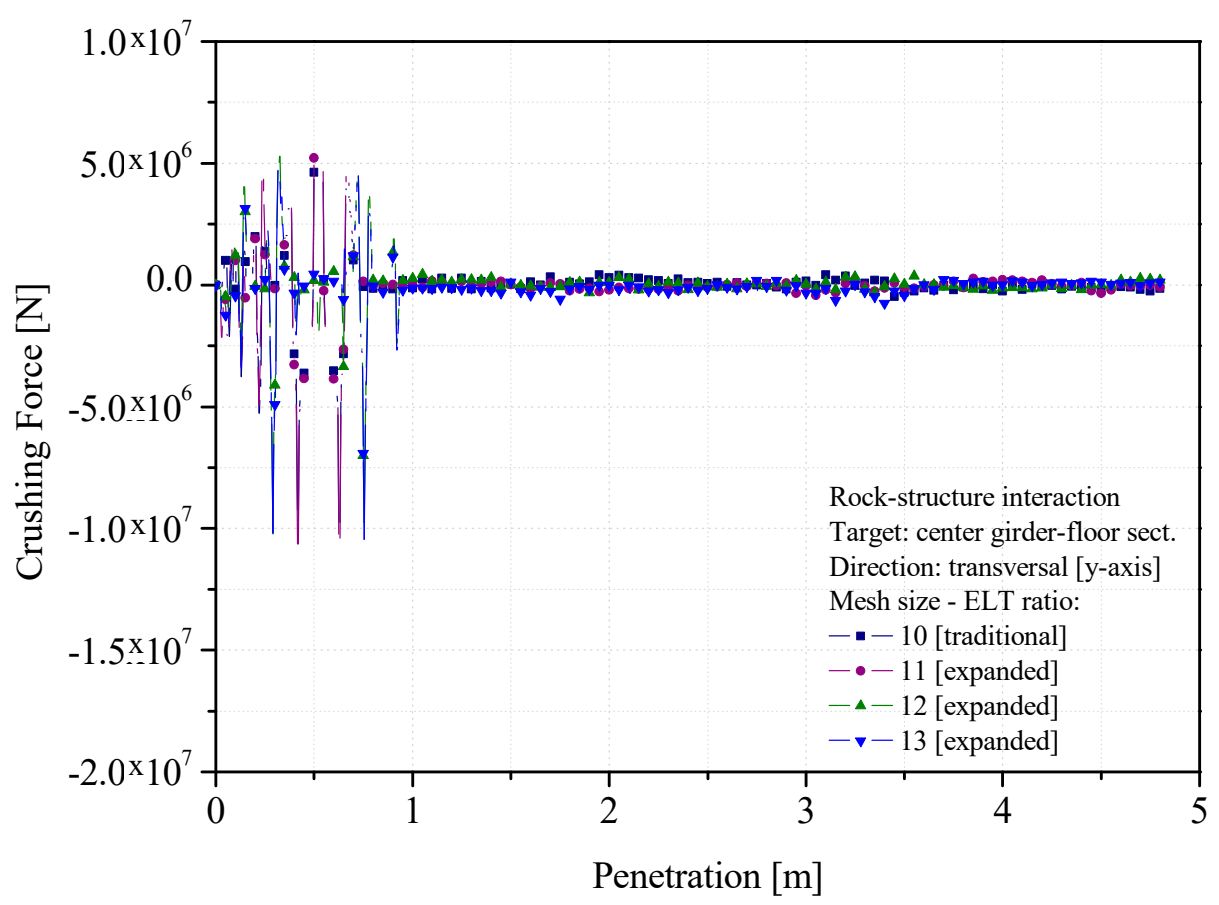

Figure 6. Variation of crushing force in the transverse direction (y-axis).

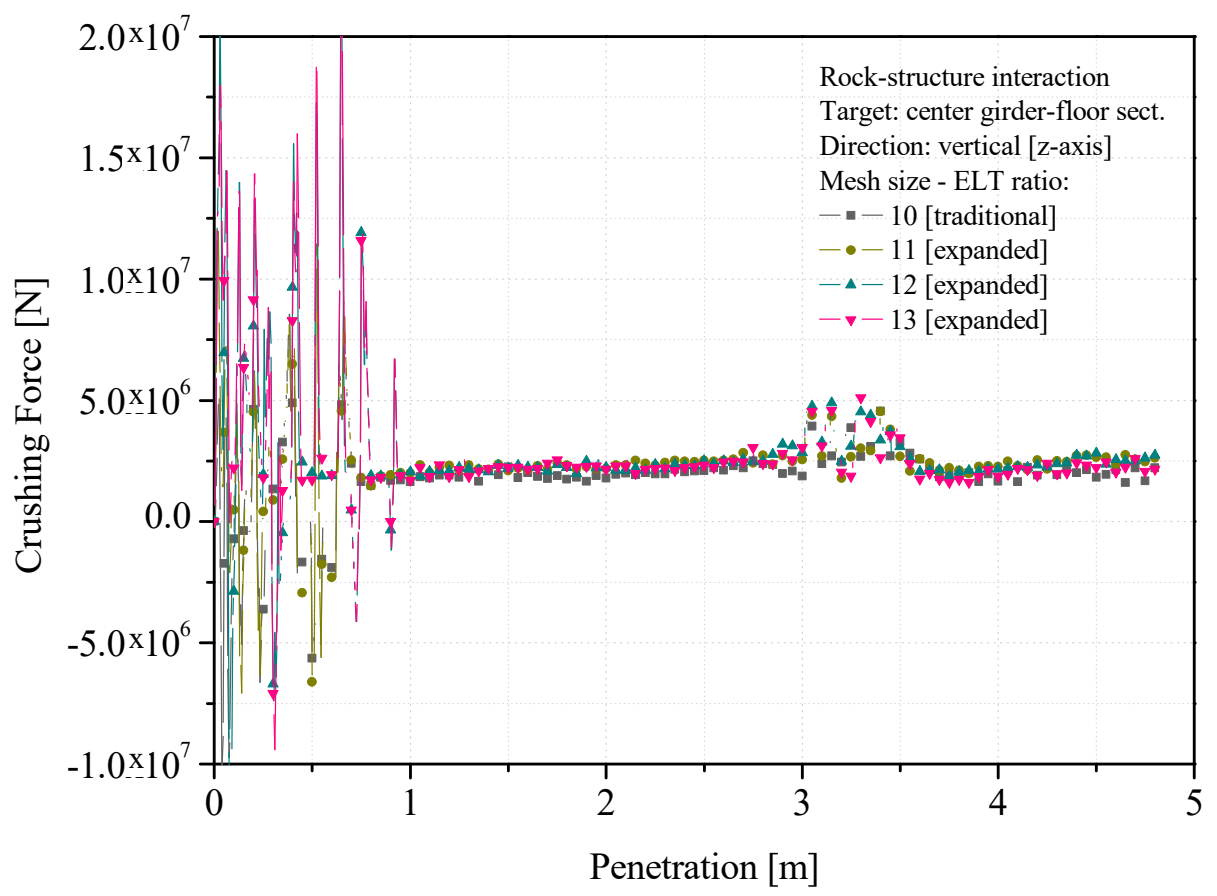

Figure 7. Variation of crushing force in the vertical direction (z-axis). 

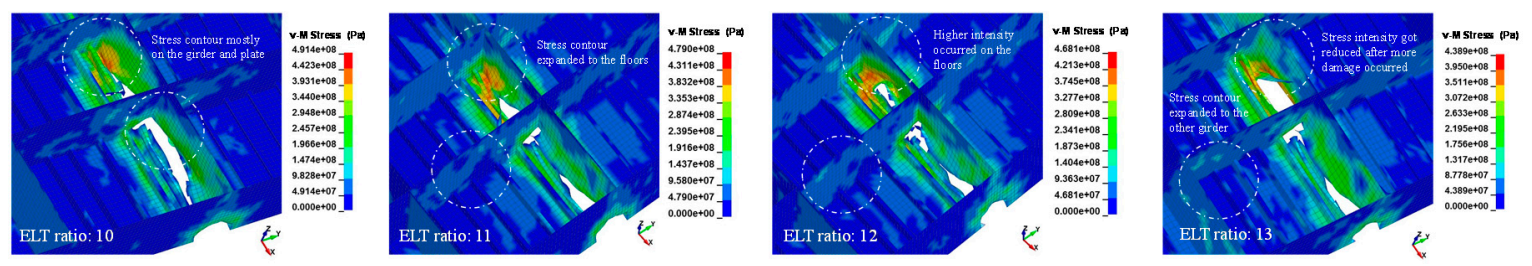

Figure 8. Stress contours (von Mises criterion) on the double bottom structures.
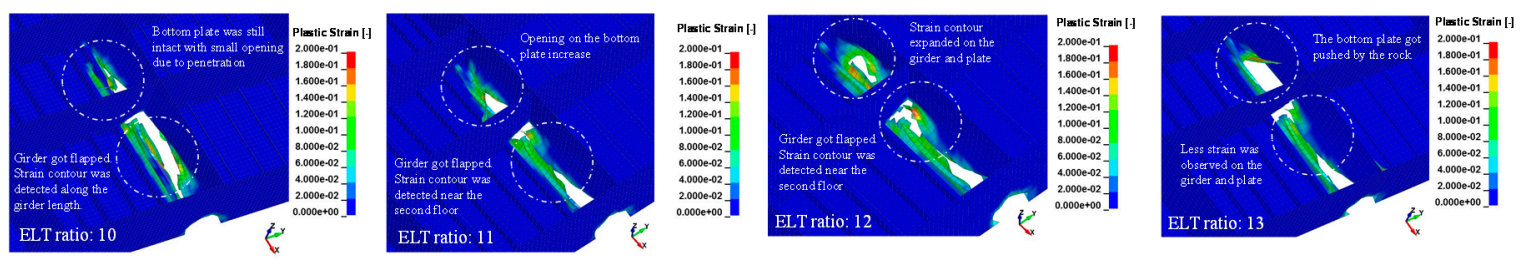

Figure 9. Strain contours (effective plastic strain) for different ELT ratios.

Even though the material cost is reduced to zero, the experiment using numerical approach tends to suffer from large disadvantages while assuming a suitable setting and configuration are not obtained. The simulation times for the current study are shown in Table 8. The traditional ELT ratio of 10, having the smallest mesh size, was associated with the largest simulation time (4500 s). Meanwhile, using an ELT ratio of 11 reduced the simulation time by more than $40 \%$. However, for an ELT ratio of 12, the simulation time was $11 \%$ larger than that for an ELT ratio of 11 . The lowest simulation time (1448 s) was obtained for an ELT ratio of 13, being around 45\% lower than that for an ELT ratio of 12.

Table 8. Calculation time of the selected ELT ratios.

\begin{tabular}{cccc}
\hline No. & Selected Ratio & No. of Elements & Simulation Time (s) \\
\hline 1 & 10 (traditional) & $>127,000$ & \pm 4500 \\
2 & 11 (expanded) & $>93,000$ & \pm 2400 \\
3 & 12 (expanded) & $>87,000$ & \pm 2700 \\
4 & 13 (expanded) & $>73,000$ & \pm 1448 \\
\hline
\end{tabular}

\subsection{Structural Acceleration}

The final criterion that was investigated in this study was structural acceleration (Figure 10). The results were divided into two areas, Area 1 and Area II. Area I covered the penetration range of 0-3 $\mathrm{m}$ and Area II covered the range of 3-5 m. A lower limit of structural acceleration was designated for Area I, and the acceleration did not exceed this limit for the investigated ELT ratios.

In Area I, the effect of acceleration on the structure was not widespread, as the medium involved in the RSI was limited to the girder and plate. In Area II, an upper limit for structural acceleration was applied, since the peak state was achieved in this range. Structural acceleration on the structure expanded aggressively, especially during impact between the x-intersection (girder and floor connection) with the rock. As the ELT ratio was increased from 10 to 12, the upper and lower acceleration limits steadily increased; however, when the ELT ratio was increased from 12 to 13 , the limits reduced by approximately $7 \%$. This observation is related to the complex connections in the ship, and it was expected. In another perspective, this finding can be concluded as mark that larger ELT ratio than 12 will give insignificant influence to structural crashworthiness. It is challenging to fully quantify nonlinear dynamic events, such as accidental loads, as this requires extensive observations of scenarios/case studies. Future work should expand the scenarios of ship accidents. 


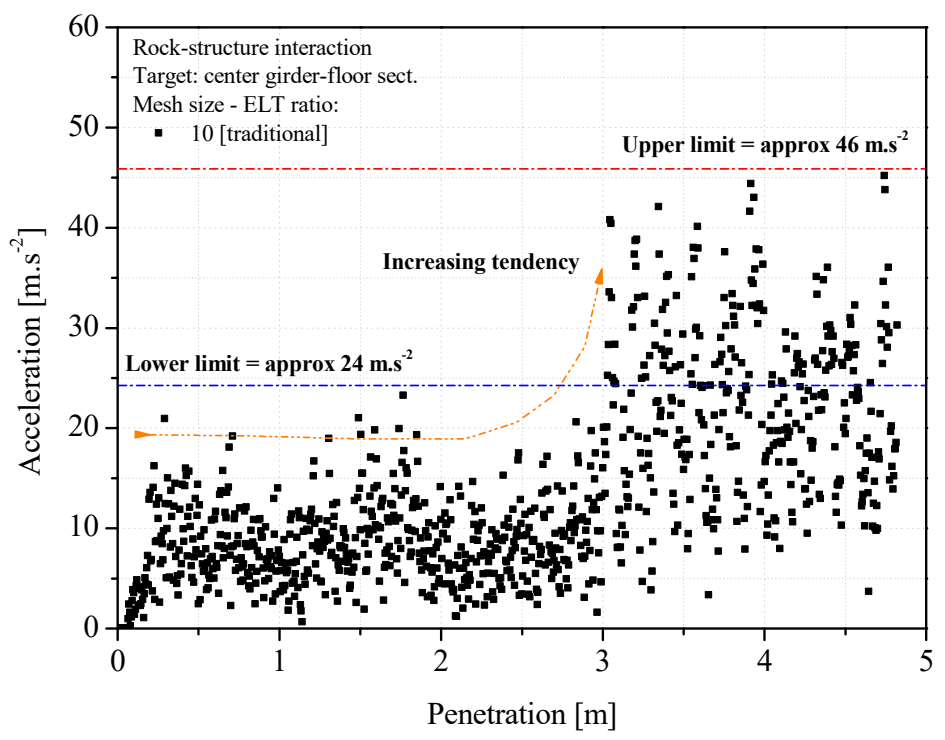

(a)

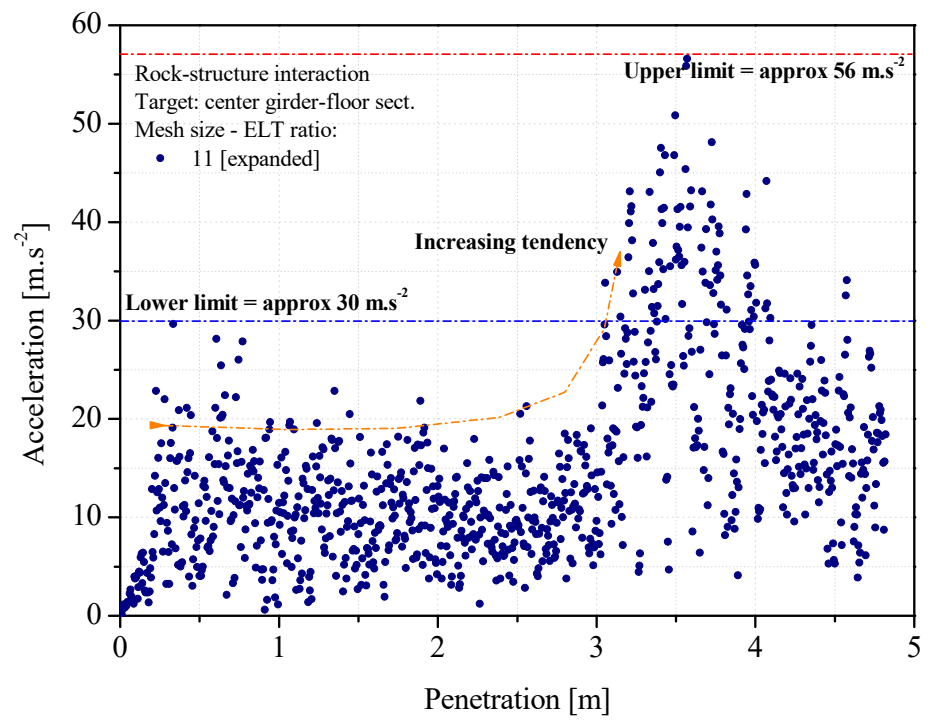

(b)

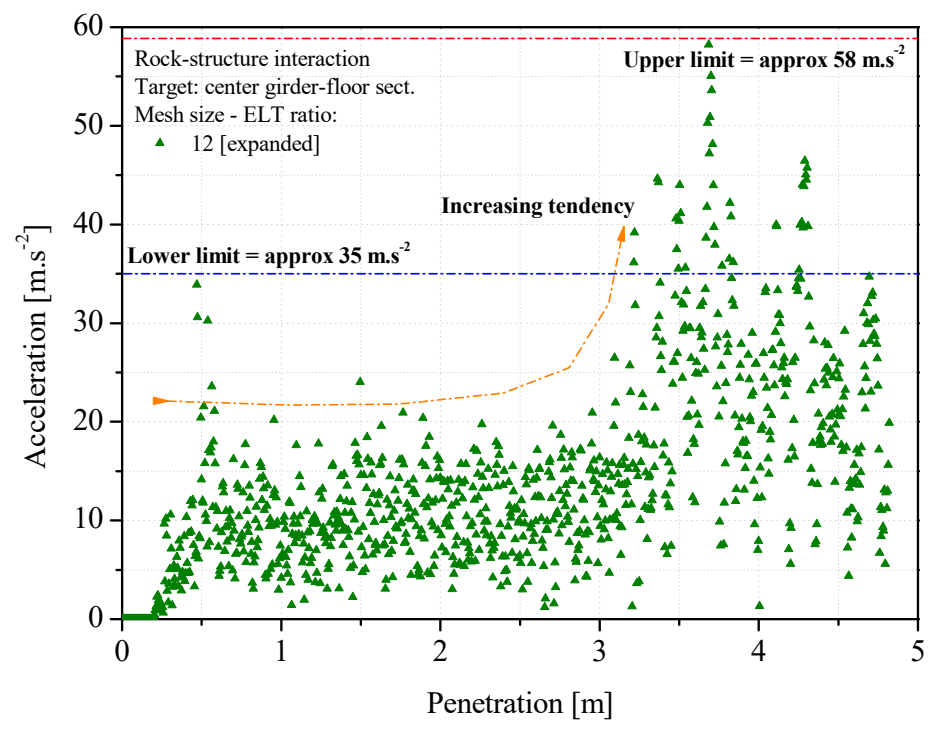

(c)

Figure 10. Cont. 


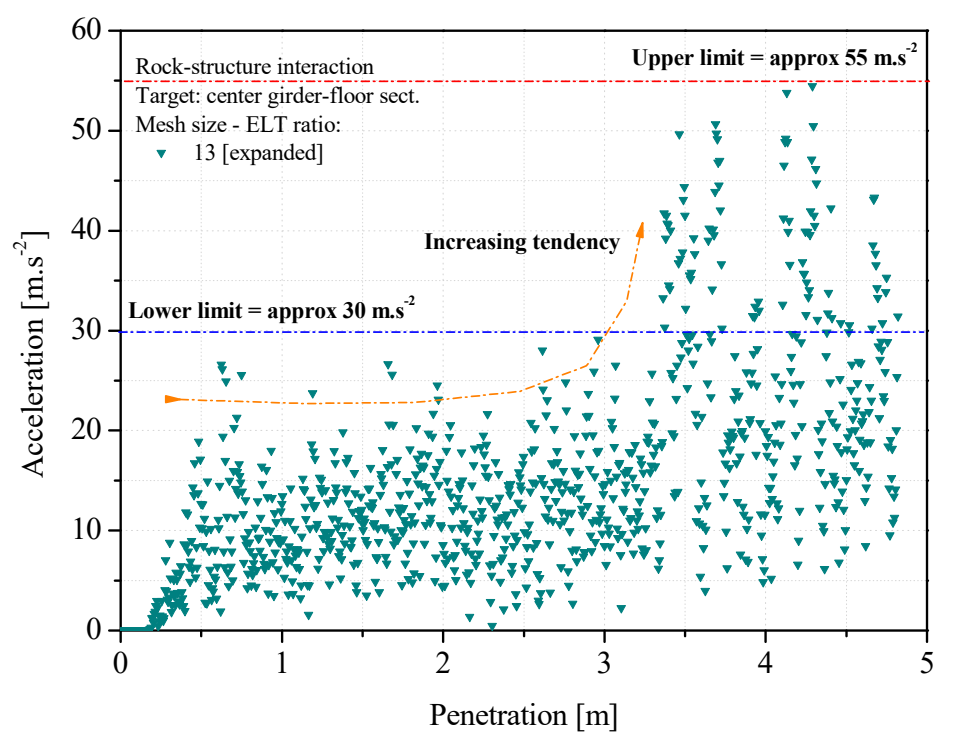

(d)

Figure 10. Simulated acceleration tendency of the ship structures with increasing rock penetration for ELT ratios of (a) 10, (b) 11, (c) 12, and (d) 13.

\section{Conclusions}

This research addressed the effect of the element-length-to-thickness (ELT) ratio on the geometry of numerical simulations. The structural response was simulated in an idealized ship-grounding scenario involving rock-structure interactions (RSI) while using a finite element method. A traditional ELT ratio was selected and compared to several expanded ELT ratios. Simulations of the internal energy showed a significant difference between ELT ratios of 11 and 12. Additionally, simulations of crushing force were conducted, with the results being similar to those that were obtained for internal energy for all force directions (longitudinal, transverse, and vertical). Furthermore, it was observed that, in the RSI scenario, the greatest damage to the structure occurred in the longitudinal ( $x$-axis) and vertical (y-axis) directions. The contours of stress and strain indicated the expansion and reduction of stress level on the residual element after the impact, as more coarse elements were more prone to experience failure. This finding was verified by the fact that a larger strain damage tear in the ship was simulated for an ELT ratio of 13 relative to the other ratios. Moreover, successively higher limits of structural acceleration were observed when the ELT ratio was increased from 10-12. Based on these results, the expansion of the mesh size in structural analysis is only recommended until an ELT ratio of 13 .

Considering an ELT ratio of 13 gained more attention, as quantification of the current results was not perfectly satisfied. However, for complex analysis and under limited computational performance, this ratio is recommended for the simulation of deformable geometries, as the results that were obtained in the present study did not show a significant difference between the results for different ELT ratios. Future research should expand the analysis that was conducted in this study to actual tests and numerical experiments to investigate mesh convergence in order to quantify the effect of mesh size in terms of the simulation time and force/damage ratio.

Author Contributions: All the authors contributed equally to the paper's preparation.

Funding: This is an independent project with no grant funding based on collaboration of Laboratory of Design and Computational Mechanics, Universitas Sebelas Maret, and Laboratory of Ship Structure and Vibration Analysis, Pukyong National University.

Conflicts of Interest: The authors declare no conflict of interest. 


\section{References}

1. Tabri, K.; Matusiak, J.; Varsta, P. Sloshing interaction in ship collisions-An experimental and numerical study. Ocean Eng. 2009, 36, 1366-1376. [CrossRef]

2. Pedersen, P.T. Review and application of ship collision and grounding analysis procedures. Mar. Struct. 2010, 23, 241-262. [CrossRef]

3. Prabowo, A.R.; Muttaqie, T.; Sohn, J.M.; Bae, D.M. Nonlinear analysis of inter-island RoRo under impact: Effects of selected collision's parameters on the crashworthy double-side structures. J. Braz. Soc. Mech. Sci. Eng. 2018, 40, 248. [CrossRef]

4. Bathe, K.J. Finite Element Procedures; Prentice-Hall, Inc.: Upper Saddle River, NJ, USA, 1996.

5. Alsos, H.S.; Amdahl, J. On the resistance of tanker bottom structures during stranding. Mar. Struct. 2007, 20, 218-237. [CrossRef]

6. Kõrgesaar, M. The effect of low stress triaxialities and deformation paths on ductile fracture simulations of large shell structures. Mar. Struct. 2019, 63, 45-64. [CrossRef]

7. Prabowo, A.R.; Bahatmaka, A.; Cho, J.H.; Sohn, J.M.; Bae, D.M.; Samuel, S.; Cao, B. Analysis of Structural Crashworthiness on a Non-Ice Class Tanker during Stranding Accounting for the Sailing Routes; Soares, C.G., Teixeira, A.P., Eds.; Taylor \& Francis Group: London, UK, 2018.

8. Ozguc, O.; Das, P.K.; Barltrop, N. A comparative study on the structural integrity of single and double side skin bulk carriers under collision damage. Mar. Struct. 2005, 18, 511-547. [CrossRef]

9. Haris, S.; Amdahl, J. Analysis of ship-ship collision damage accounting for bow and side deformation interaction. Mar. Struct. 2013, 32, 18-48. [CrossRef]

10. Prabowo, A.R.; Bae, D.M.; Sohn, J.M.; Zakki, A.F.; Cao, B.; Cho, J.H. Effects of the rebounding of a striking ship on structural crashworthiness during ship-ship collision. Thin-Walled Struct. 2017, 115, 225-239. [CrossRef]

11. Yu, Z.; Hu, Z.; Amdahl, J.; Liu, Y. Investigation on structural performance predictions of double-bottom tankers during shoal grounding accidents. Mar. Struct. 2013, 33, 188-213. [CrossRef]

12. Sormunen, O.V.E.; Kõrgesaar, M.; Tabri, K.; Heinvee, M.; Urbel, A.; Kujala, P. Comparing rock shape models in grounding damage modelling. Mar. Struct. 2016, 50, 205-223. [CrossRef]

13. Prabowo, A.R.; Bae, D.M.; Cho, J.H.; Sohn, J.M. Characteristic of double bottom responses under powered-hard grounding scenario with idealised rock indenter. Int. J. Struct. Eng. 2018, 9, 130-144. [CrossRef]

14. Qiankun, J.; Gangyi, D. A finite element analysis of ship sections subjected to underwater explosion. Int. J. Impact Eng. 2011, 38, 558-566. [CrossRef]

15. Ming, F.R.; Zhang, A.M.; Xue, Y.Z.; Wang, S.P. Damage characteristics of ship structures subjected to shockwaves of underwater contact explosions. Ocean Eng. 2016, 117, 359-382. [CrossRef]

16. Minorsky, V.U. An analysis of ship collision with reference to protection of nuclear power ships. J. Ship Res. 1958, 3, 1-4.

17. Woisin, G. Design against collision. Schiff Hafen 1979, 31, 1059-1069.

18. Simonsen, B.C.; Törnqvist, R. Experimental and numerical modelling of ductile crack propagation in large-scale shell structures. Mar. Struct. 2004, 17, 1-27. [CrossRef]

19. Alsos, H.S.; Amdahl, J. On the resistance to penetration of stiffened plates, Part I-Experiments. Int. J. Impact Eng. 2009, 36, 799-807. [CrossRef]

20. Prabowo, A.R.; Bae, D.M.; Sohn, J.M.; Zakki, A.F.; Cao, B.; Wang, Q. Analysis of structural damage on the struck ship under side collision scenario. Alex. Eng. J. 2018, 57, 1761-1771. [CrossRef]

21. Reardon, P.; Sprung, J.L. Validation of Minorsky's ship collision model and use of the model to estimate the probability of damaging a radioactive material transportation cask during a ship collision. In Proceedings of the International Conference on Design and Methodologies for Collision and Grounding Protection of Ships, San Francisco, CA, USA, 22-23 August 1996.

22. Zhiqiang, H.; Jørgen, A.; Lin, H. Verification of a simplified analytical method for predictions of ship groundings over large contact surfaces by numerical simulations. Mar. Struct. 2011, 24, 436-458. [CrossRef]

23. Prabowo, A.R.; Sohn, J.M.; Bae, D.M.; Setiyawan, A. Crashworthiness assessment of thin-walled bottom structures during powered-hard grounding accidents. In Proceedings of the ASME 37th International Conference on Ocean, Offshore and Arctic Engineering, Madrid, Spain, 17-22 June 2018. [CrossRef]

24. AbuBakar, A.; Dow, R.S. Simulation of ship grounding damage using the finite element method. Int. J. Solids Struct. 2013, 50, 623-636. [CrossRef] 
25. Zong, Z.; Zhao, Y.; Li, H. A numerical study of whole ship structural damage resulting from close-in underwater explosion shock. Mar. Struct. 2013, 31, 24-43. [CrossRef]

26. ANSYS. ANSYS LS-DYNA User's Guide; ANSYS, Inc.: Canonsburg, PA, USA, 2019.

27. ANSYS. ANSYS Mechanical APDL Element Reference; ANSYS, Inc.: Canonsburg, PA, USA, 2019.

28. Camargo, F.V.D. Survey on experimental and numerical approaches to model underwater explosions. J. Mar. Sci. Eng. 2019, 7, 15. [CrossRef]

29. Zhang, S. The Mechanics of Ship Collisions; Technical University of Denmark: Lyngby, Denmark, 1999.

30. Wierzbicki, T.; Thomas, P. Closed form solution for wedge cutting force through thin metal sheets. Int. J. Mech. Sci. 1993, 35, 209-229. [CrossRef]

31. Simonsen, B.C.; Wierzbicki, T. Plasticity, fracture and friction in steady state plate cutting. Int. J. Impact Eng. 1998, 21, 387-411. [CrossRef]

32. Lamb, T.; Brown, R.L. The size and speed of tankers: Recent improvements in construction. Naval Eng. J. 1952, 64, 161-168. [CrossRef]

33. Törnqvist, R. Design of Crashworthy Ship Structures; Technical University of Denmark: Lyngby, Denmark, 2003.

34. Prabowo, A.R. Crashworthiness Assessment of Ship Structures under Collision and Grounding; Pukyong National University: Busan, South Korea, 2018.

35. Prusty, B.G.; Satsangi, S.K. Analysis of stiffened shell for ships and ocean structures by finite element method. Ocean Eng. 2001, 28, 621-638. [CrossRef]

(C) 2019 by the authors. Licensee MDPI, Basel, Switzerland. This article is an open access article distributed under the terms and conditions of the Creative Commons Attribution (CC BY) license (http://creativecommons.org/licenses/by/4.0/). 